\title{
On inferring isoprene emission surface flux from atmospheric boundary layer concentration measurements
}

\author{
J. Vilà-Guerau de Arellano ${ }^{1}$, K. van den Dries ${ }^{1}$, and D. Pino ${ }^{2}$ \\ ${ }^{1}$ Meteorology and Air Quality Section, Wageningen University, The Netherlands \\ ${ }^{2}$ Applied Physics Department, Technical University of Catalonia and Institute for Space Studies of Catalonia, Spain
}

Received: 14 November 2008 - Published in Atmos. Chem. Phys. Discuss.: 9 February 2009

Revised: 17 April 2009 - Accepted: 5 May 2009 - Published: 4 June 2009

\begin{abstract}
We examine the dependence of the inferred isoprene surface emission flux from atmospheric concentration on the diurnal variability of the convective boundary layer (CBL). A series of systematic numerical experiments carried out using the mixed-layer technique enabled us to study the sensitivity of isoprene fluxes to the entrainment process, the partition of surface fluxes, the horizontal advection of warm/cold air masses and subsidence. Our findings demonstrate the key role played by the evolution of boundary layer height in modulating the retrieved isoprene flux. More specifically, inaccurate values of the potential temperature lapse rate lead to changes in the dilution capacity of the CBL and as a result the isoprene flux may be overestimated or underestimated by as much as $20 \%$. The inferred emission flux estimated in the early morning hours is highly dependent on the accurate estimation of the discontinuity of the thermodynamic values between the residual layer and the rapidly forming CBL. Uncertainties associated with the partition of the sensible and latent heat flux also yield large deviations in the calculation of the isoprene surface flux. Similar results are obtained if we neglect the influence of warm or cold advection in the development of the CBL. We show that all the above-mentioned processes are non-linear, for which reason the dynamic and chemical evolutions of the CBL must be solved simultaneously. Based on the discussion of our results, we suggest the measurements needed to correctly apply the mixed-layer technique in order to minimize the uncertainties associated with the diurnal variability of the convective boundary layer.
\end{abstract}



Correspondence to:

J. Vilà-Guerau de Arellano

(jordi.vila@wur.nl)

\section{Introduction}

Atmospheric chemistry is largely driven by the surface emissions of atmospheric compounds, mainly nitrogen oxides and biogenic volatile organic compounds (VOC), in regions dominated by forest and agriculture. The latter play a key role in controlling the oxidizing capacity of the atmosphere (Fuentes et al., 2000). Oxidation levels thus depend on the VOC emitted into the atmospheric boundary layer (ABL) and the capacity of the ABL to dilute, mix and transform the VOC.

Atmospheric turbulence rapid fluctuations drive the surface fluxes. These measurements are difficult and costly to be taken continuously, and consequently observations of upper air atmospheric concentrations made in experimental field campaigns are used to infer surface emission fluxes The inferred techniques are based on ABL methods such as the mixed-layer theory, the mixed-layer gradient or the variance methods (Zimmerman et al., 1988; Davis et al., 1994; Guenther et al., 1996; Helmig et al., 1998; Westberg et al., 2001; Spirig et al., 2004; Karl et al., 2007). An important additional benefit of using these techniques is the derivation of surface emission fluxes that are representative of larger regions than single-point measurements (Spirig et al., 2004).

Although some assumptions associated with the use of these techniques have been mentioned in these experimental studies (Guenther et al., 1996; Lauback and Fritsch, 2002), to the best of our knowledge a thorough analysis has yet to be made of the implications of these assumptions related to the uncertainties in boundary layer development. In order to attain these goals, therefore, our study had the following objectives:

1. To determine the role of the diurnal variability of the atmospheric boundary layer in estimating the surface fluxes from upper atmospheric concentration measurements. 
2. To assess the uncertainties on the specific processes and their diurnal evolution in inferring the fluxes using the mixed-layer method (or mixed-box technique).

3. To provide concrete suggestions for future field atmospheric chemistry campaigns in order to reduce the uncertainty associated with the diurnal evolution of CBL processes.

As point 2 above states, this study focuses entirely on mixedlayer theory, but our analysis and discussion are also applicable to other methods such as the mixed-layer gradient and the mixed-layer variance (Davis et al., 1994; Helmig et al., 1998; Karl et al., 2007), since both techniques are heavily dependent on accurate estimates of the diurnal evolution of atmospheric boundary layer variables.

This paper is structured as follows. In the next section, we briefly review the fundamental concepts of mixed-layer theory. We stress the need to couple the boundary layer dynamic model to a chemistry module in order to account for the role of diurnal variability. Doing so, offers us a balance between the source and sink processes that occur at the surface and the dilution rate and exchange rate between the CBL and free troposphere which together determine the evolution of the reactants. At this point, it is important to mention that in the current study we have focused our analysis on isoprene because of its key role in atmospheric chemistry (Fuentes et al., 2000). However, the results and discussion are also valid in the estimation of other biogenic emission fluxes.

Section 3 presents the sensitivity analysis of the inferred fluxes to the variables and conditions that determine the evolution of the CBL. We briefly discuss and quantify the roles played by the following conditions: (a) the upper free atmosphere conditions in the CBL inversion, or entrainment zone, during the transition between the night and diurnal conditions (b) the evolution in time of surface forcing, represented by the sensible heat and latent heat fluxes and (c) the role of warm or cold advection and subsidence in the development of the CBL. We close the paper by providing a list of suggestions for improving the determination of surface fluxes for reactive species in future experimental field/campaigns.

\section{Reactants in an evolving convective boundary layer}

Our study reproduces the diurnal variation of the chemistry in the atmospheric boundary layer above a tropical forest. Because of its importance in determining the atmospheric oxidation capacity in this region, several experimental campaigns have been carried out, including the NASA Global Tropospheric Experiment (GTE) (Zimmerman et al., 1988), Amazon Boundary Layer Experiment 2A (ABLE-2) (Zimmerman et al., 1988; Davis et al., 1994); Large-Scale Biosphere-Atmosphere Experiment in Amazonia (LBA-EUSTACH) (Andreae et al., 2002); the Tropical
Forest and Fire Emission Experiment (TROFEE) (Yokelson et al., 2007) and Guayanas Atmosphere-Biosphere exchange and Radicals Intensive Experiment with the Learjet (GABRIEL) (Eerdekens et al., 2008) all of which aimed at determining the main characteristics of atmospheric chemistry in this region. Although our meteorological and chemistry conditions are characteristic of the tropical forest region, the methodology employed in these experiments and the sensitivity analysis can also be applied to other Earth's regions and only require adjusting the boundary and initial conditions to the specific area.

\subsection{Mixed-layer model coupled to a chemical module}

Our main aim is to mimic the research strategy employed in the analysis of field observations collected at experiments (Guenther et al., 1996; Spirig et al., 2004; Karl et al., 2007). In order to reproduce accurately the diurnal variability of the CBL, we make use of a mixed-layer model coupled to a chemistry module. This enables us to describe the essential components of the CBL evolution, while retaining a simple description for the main processes such as turbulent mixing or entrainment. Similarly, the chemistry retains the essential reactions of the $\mathrm{O}_{3}-\mathrm{NO}_{\mathrm{x}}-\mathrm{CO}-\mathrm{VOC}$ system, where the VOC represents the isoprene atmospheric compound.

The mixed boundary-layer model (from now on MXL) is based on the studies performed by Lilly (1968); Betts (1973); Carson (1973); Tennekes (1973) and Fedorovich (1995). In brief, we solve two basic equations for the mixed layer mean value $(<S>)$ and for the discontinuity jump at the inversion $(\Delta S)$. Both equations are the result of vertically integrating the conservation equation for heat, moisture, momentum and the reactants in the mixed layer region and the entrainment zone, respectively.

The system of prognostic equations for the generic scalar variable ( $s=\theta_{v}, q$, or a chemical species) reads:

$$
\begin{gathered}
\frac{\partial<S>}{\partial t}=\frac{\left[(\overline{w s})_{s}-(\overline{w s})_{e}\right]}{h}- \\
\left(U \frac{\partial<S>}{\partial x}+V \frac{\partial<S>}{\partial y}\right)+R \\
\frac{\partial \Delta S}{\partial t}=\gamma_{s}\left(\frac{\partial h}{\partial t}-w_{s}\right)-\frac{\partial<S>}{\partial t}= \\
\gamma_{s} w_{e}-\frac{\partial<S>}{\partial t} .
\end{gathered}
$$

Equation (1) shows that in the CBL the tendency term of any scalar depends on the vertical turbulent flux difference between the surface and entrainment zone, the horizontal advection and, for the chemically active species, also their chemical transformation $(R)$. The evolution of the discontinuity or jump value $\Delta S$ at the entrainment zone, see Eq. (2), is a function of the tendency value at the residual layer or free troposphere (first term right-hand side) and the evolution of 
the mixed layer value (2nd term r.h.s). Above the jump, the profile of each variable in the free troposphere is dependent on the vertical gradient $\left(\gamma_{s}\right)$ and on the mean subsidence vertical velocity $\left(w_{s}\right)$. This velocity is normally opposite to the boundary layer growth, i.e., subsidence $w_{s}<0$. This set of equations is completed by adding the mixed-layer equations for $U$ and $V$, together with their respective Coriolis term. These equations are necessary to include the advection term adequately.

At this point, it is important to mention that the dynamic evolution of the CBL is solely driven by the heat introduced in the CBL, represented by the virtual potential temperature $\left(s=\theta_{v}\right)$ variable. From the equation system (1-2), this variable requires a different assumption for the heat flux in the entrainment zone. Consequently, the entrainment velocity $\left(w_{e}\right)$ introduced at Eq. (2) is related to the boundary layer growth $\frac{\partial h}{\partial t}$ and the mean subsidence vertical velocity. In mixed-layer theory, we assume that $w_{e}$ is a function of the entrainment flux and the jump in the virtual potential temperature in the inversion layer. This assumption is known as zero-order closure and it was first suggested by Lilly (1968). It is expressed mathematically by:

$w_{e}=\frac{\partial h}{\partial t}-w_{s}=-\frac{\left(\overline{w \theta_{v}}\right)_{e}}{\Delta \theta_{v}}$.

Equation (3) assumes that the inversion is characterized by a sharp discontinuity. Under conditions of weak inversion, it is convenient to include explicitly the inversion depth requiring a modification of Eq. (3) (Kim et al., 2006). For $\theta_{v}$, Eqs. (1-3) contain seven variables: $h,\left\langle\theta_{v}\right\rangle$, $\Delta \theta_{v},\left(\overline{w \theta_{v}}\right)_{s},\left(\overline{w \theta_{v}}\right)_{e}, \gamma_{\theta_{v}}$ and $w_{s}$. The first three are solved by the system (1-3) whereas the other four need to be prescribed or calculated using additional equations or closure assumptions. Below, we provide the usual procedure in prescribing or calculating these variables.

The heat and moisture surface fluxes are either prescribed based on field measurements or calculated using a coupled land-surface scheme. The subsidence velocity $\left(w_{s}\right)$ and the potential temperature lapse rate in the free troposphere depend on the atmosphere at large scales. These upper boundary conditions are thus obtained either from large-scale models or by a radiosounding taken in the early morning hours of the CBL development. In consequence, to close the set of Eqs. (1), (2) and (3), we still need to relate the entrainment of heat flux to the surface flux. We assume the following relation $\left(\overline{w \theta_{v}}\right)_{e}=-\beta\left(\overline{w \theta_{v}}\right)_{s}$, where $\beta=0.2$, i.e. the entrainment flux is related to the surface flux and it represents an additional 20\% entrainment of warm air into the CBL. Here, it needs to be mentioned that the $\beta$-value can increase, depending on the contribution of shear in the CBL development (Angevine et al., 1998; Pino et al., 2003; Conzemius and Fedorovich, 2006); in our study we have assumed a constant value.

For the reactants, we only need to solve Eqs. (1-2). Surface fluxes are either prescribed, in which case we obtain the
Table 1. Chemical reaction scheme couple to the dynamics of the MXL model. It includes the dependence of the photodissociation rate for Reactions (R2) (units $s^{-1}$ ) on the diurnal variation of the zenith angle zen (Dickerson et al., 1982). Photodissociation rate for (R1) follows the same diurnal behviour as (R2), but its maximum value has been adjusted according to its order of magnitude. The reaction coefficients for the second-order reaction $\mathrm{k}\left(\mathrm{ppbv}^{-1} \mathrm{~s}^{-1}\right)$ are taken from Stockwell et al. (1990).

\begin{tabular}{ccc}
\hline Num & Reaction & $k$ \\
\hline $\mathrm{R} 1$ & $\mathrm{O}_{3} \stackrel{\mathrm{H}_{2} \mathrm{O}}{\rightarrow} 2 \mathrm{OH}+\mathrm{O}_{2}$ & $1.67 \times 10^{-2} e^{(-0.575 / \cos (\mathrm{zen}))}$ \\
$\mathrm{R} 2$ & $\mathrm{NO}_{2} \stackrel{\mathrm{O}_{2}}{\rightarrow} \mathrm{NO}+\mathrm{O}_{3}$ & $5.07 \times 10^{-6} e^{(-0.575 / \cos (\mathrm{zen}))}$ \\
$\mathrm{R} 3$ & $\mathrm{NO}+\mathrm{O}_{3} \rightarrow \mathrm{NO}_{2}+\mathrm{O}_{2}$ & $4.43 \times 10^{-4}$ \\
$\mathrm{R} 4$ & $\mathrm{OH}+\mathrm{CO} \stackrel{\mathrm{O}_{2}}{\rightarrow} \mathrm{HO}_{2}+\mathrm{CO}_{2}$ & $5.90 \times 10^{-3}$ \\
$\mathrm{R} 5$ & $\mathrm{OH}+\mathrm{ISO} \rightarrow \mathrm{HO}_{2}+\mathrm{Prd}$ & 1.772 \\
$\mathrm{R} 6$ & $\mathrm{HO}{ }_{2}+\mathrm{NO} \rightarrow \mathrm{OH}_{+} \mathrm{NO}_{2}$ & $2.17 \times 10^{-1}$ \\
$\mathrm{R} 7$ & $\mathrm{HO}{ }_{2}+\mathrm{O}_{3} \rightarrow \mathrm{OH}_{2} \mathrm{O}_{2}$ & $4.92 \times 10^{-5}$ \\
$\mathrm{R} 8$ & $2 \mathrm{HO}_{2} \rightarrow \mathrm{H}_{2} \mathrm{O}_{2}+\mathrm{O}_{2}$ & $7.13 \times 10^{-2}$ \\
$\mathrm{R} 9$ & $\mathrm{OH}+\mathrm{NO}_{2} \rightarrow \mathrm{HNO}_{3}$ & $2.71 \times 10^{-1}$ \\
$\mathrm{R} 10$ & $\mathrm{OH}+\mathrm{O}_{3} \rightarrow \mathrm{HO}_{2}+\mathrm{O}_{2}$ & $1.67 \times 10^{-3}$ \\
$\mathrm{R} 11$ & $\mathrm{OH}+\mathrm{HO}_{2} \rightarrow \mathrm{H}_{2} \mathrm{O}+\mathrm{O}_{2}$ & 2.708 \\
\hline
\end{tabular}

diurnal evolution of the reactants, or they are calculated from the atmospheric boundary layer concentration measurements (Guenther et al., 1996; Spirig et al., 2004; Karl et al., 2007), as we will discuss in Sect. 3.

In order to solve Eqs. (1-2), we still require a closure assumption for the entrainment flux, $(\overline{w s})_{e}$, at the top of the ABL. This expression needs to relate this flux to the ABL growth rate $\frac{\partial h}{\partial t}$ and to the scale properties in and above the $\mathrm{ABL}$. We can therefore assume that the entrainment flux is defined as (Betts, 1992):

$(\overline{w s})_{e}=-w_{e} \Delta S$.

This closure assumption requires us to calculate the entrainment velocity and the difference in the scalar values between the free troposphere and the boundary layer. A zeroorder jump scheme ( $\Delta S=S_{F T}-<S>$ ) is assumed to represent the discontinuity between the values of the free troposphere $\left(S_{F T}\right)$ and the mixed layer. The $S_{F T}$ is assumed to be constant in space and time for the variables $\theta_{v}$ and $q$; i.e., there are no changes in its synoptic characteristics. However, 


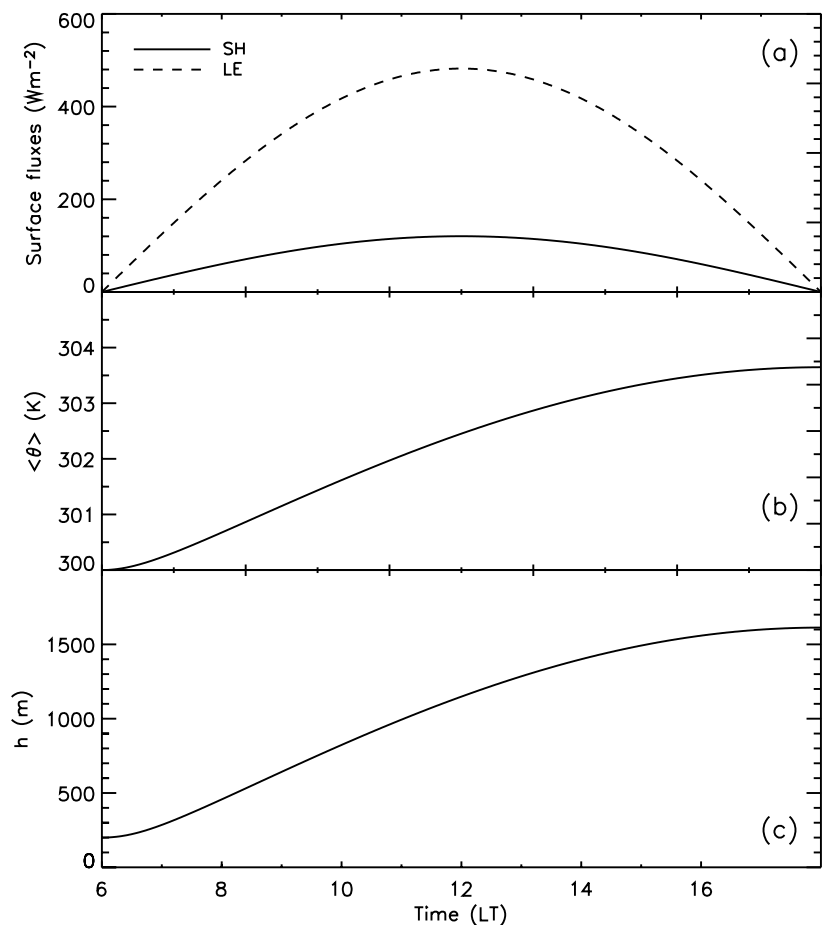

Fig. 1. Diurnal evolution of the (a) prescribed sensible and latent heat fluxes, (b) calculated mixed-layer potential temperature and (c) calculated boundary layer height. The initial and boundary conditions prescribed and used in the reference case in the MXL model are shown in Table 2 .

reactants are chemically transformed in the free troposphere, and $S_{F T}$ therefore varies for the reactants.

Finally, the chemical mechanism is summarized in Table 1 . It contains the basic chemical reactions in the $\mathrm{O}_{3}$ $\mathrm{NO}_{\mathrm{x}}$-VOC-CO system, and it has previously been used to describe the influence of turbulence on chemistry (Krol et al., 2000). Because of its importance where VOC compounds are concerned, we focus solely on isoprene (ISO). However, to compensate the absence of other biogenic compounds, we increase the reaction rate of $\mathrm{R} 5$ by a factor 10 from the given value by Stockwell et al. (1990). We are aware that this is a rather simple scheme that omits certain other important organic species. However, as we show in the next section, this scheme is able to reproduce the observed diurnal variability of the main reactants involved in the oxidizing capacity of the Amazonian region.

\subsection{Diurnal evolution of the dynamics and chemistry}

The Amazonian convective boundary layer is characterized by low values of the Bowen ratio and a relative weak capping inversion. The chemistry is driven by the relative high VOC and low $\mathrm{NO}_{\mathrm{x}}$ emissions which yield to a diurnal variation with maximum mixing ratio oscillating between 20
Table 2. The initial values (subscript $o$ ) and prescribed surface flux (subscript $s$ ) evolution used for the MXL model to calculate the evolution of the boundary layer dynamics and reactants for the reference numerical experiment. A 12-h diurnal variation is assumed by prescribing $t_{d}$ to $12 \mathrm{~h}$. The integration time is $13 \mathrm{~h}$, and the first hour is used as a spin-up for the chemistry, assuming: $\left(\overline{\left.w \theta_{v}\right)_{S}}=\left(\overline{w q)_{s}}=0\right.\right.$.

\begin{tabular}{cc}
\hline$h_{o}(\mathrm{~m})$ & 200. \\
$w_{s}\left(\mathrm{~ms}^{-1}\right)$ & 0. \\
\hline Virtual potential temperature & \\
$<\theta_{v o}>(\mathrm{K})$ & 300. \\
$\Delta \theta_{v o}(\mathrm{~K})$ & 0.1 \\
$\left(w \theta_{v}\right)_{s}\left(\mathrm{~K} \mathrm{~ms}^{-1}\right)$ & $0.1 \sin \left(\frac{\pi t}{t_{d}}\right)$ \\
$\gamma_{\theta_{v}}\left(\mathrm{~K} \mathrm{~m}^{-1}\right)$ & $3.10^{-3}$ \\
$\beta_{\theta_{v}}(-)$ & 0.2 \\
\hline $\mathrm{Specific} \mathrm{humidity}>_{o}\left(\mathrm{~g} \mathrm{Kg}^{-1}\right)$ & 15. \\
$\Delta q_{o}\left(\mathrm{~g} \mathrm{Kg}^{-1}\right)$ & 0.0 \\
$(\overline{w q})_{s}\left(\mathrm{~g} \mathrm{Kg}^{-1} \mathrm{~m} \mathrm{~s}^{-1}\right)$ & $0.16 \sin \left(\frac{\pi t}{t_{d}}\right)$ \\
$\gamma_{q}\left(\mathrm{~g} \mathrm{Kg}^{-1} \mathrm{~m} \mathrm{~s}^{-1}\right)$ & 0.0 \\
\hline
\end{tabular}

$40 \mathrm{ppb}$ (Andreae et al., 2002). In Table 2, we present the initial and boundary layer values prescribed for the reference case. These values are similar to those discussed by Betts and Jacob (2002) gathered during the Large-Scale BiosphereAtmosphere (LBA) experiment in Amazonia. Figure 1 shows the prescribed values of the surface fluxes and the calculated evolution of the potential temperature and boundary layer height. The diurnal variability for $<\theta(t)>$ is very similar to that reported by Betts and Jacob (2002), with an increase of $3.5 \mathrm{~K}$ during the day. The specific moisture (not shown) also grows from $15 \mathrm{~g} \mathrm{~kg}^{-1}$ to almost $18 \mathrm{~g} \mathrm{~kg}^{-1}$ at the end of the afternoon. The boundary layer height shows a typical evolution with maximum values at the end of the afternoon above $1600 \mathrm{~m}$ (18:00 LT). The entrainment velocity (not shown) has a peak at around 08:00 LT $\left(w_{e}=4.5 \times 10^{-2} \mathrm{~ms}^{-1}\right)$, corresponding to the early morning growth; after this time it decays linearly. Notice that under these conditions, shallow cumulus may form in the early afternoon, which partially extends the dilution of the boundary layer to higher altitudes (Vilà-Guerau de Arellano et al., 2005). However, here we focus our analysis only on the sensitivity of the inferred isoprene flux under clear conditions.

Table 3 summarizes the initial reactant values in the CBL and the free troposphere. The photolysis rates correspond to 21 June at latitude $10^{\circ} \mathrm{N}$. Only two species have emission fluxes: nitric oxide with a constant flux similar to that observed by van Dijk et al. (2002) during the LBA-EUSTACH experimental campaign, and the isoprene flux which follows a sinusoidal diurnal variation inspired by the observations taken during the TROFEE campaign (Karl et al., 2007). Figure 2 shows the diurnal variation of the reactive species in the CBL calculated by the MXL model. Notice that our intention 
Table 3. Initial mixing ratio (ppbv) in the boundary layer (CBL), free troposphere (FT) and surface emission fluxes of the reactive species ( $\mathrm{ppb} \mathrm{m} \mathrm{s}^{-1}$ ) prescribed in the MXL model in the reference numerical experiment. The conversion factor to mg m $\mathrm{m}^{-2} \mathrm{~h}^{-1}$ units is divided by the factor 0.087 . A 12-h diurnal variation is assumed by prescribing $t_{d}$ to $12 \mathrm{~h}$. The integration time is $13 \mathrm{~h}$, and the first hour is used as a spin-up for the chemistry, assuming that: $\overline{(w \mathrm{ISO})_{S}}=0$.

\begin{tabular}{lcccccccc}
\hline & $\mathrm{O}_{3}$ & $\mathrm{NO}$ & $\mathrm{NO}_{2}$ & $\mathrm{ISO}$ & $\mathrm{HO}_{2}$ & $\mathrm{OH}$ & $\mathrm{CO}$ & Inert \\
\hline Mixing ratio CBL & 10.0 & 0.2 & 0.5 & 0 & 0. & 0. & 100. & 0.0 \\
Mixing ratio FT & 10.0 & 0.0 & 0.0 & 0 & 0. & 0. & 100. & 0.0 \\
Surface emission flux & 0. & $5.10^{-3}$ & 0. & $0.7 \sin \left(\frac{\pi t}{t_{d}}\right)$ & 0. & 0. & 0.0 & 1.0 \\
\hline
\end{tabular}

is not to reproduce a particular situation, but the characteristic evolution and order of magnitude of the chemical species in this specific region. In that respect, we make use of different observations collected during various experimental campaigns in the Amazon region to evaluate our MXL results. The $\mathrm{O}_{3}$-evolution shown in Fig. 2a and the $\mathrm{NO}$ and $\mathrm{NO}_{2}$ time evolution shown in Fig. 2b are therefore similar to those measured during the LBA-EUSTACH-1 campaign by Andreae et al. (2002). In brief, ozone increases during the day due to the VOC and $\mathrm{NO}_{\mathrm{x}}$ emission and the chemical transformations, since in our numerical experiment setup, there is a minimal contribution of $\mathrm{O}_{3}$-entrainment from the free troposphere, i.e., the initial values at the CBL and in the free troposphere are equal (see Table 3) and dry deposition is omitted. The observed $\mathrm{NO}$ and $\mathrm{NO}_{2}$ peaks in the early morning observed in the same campaign due to the shallow boundary layer height are well reproduced by the MXL model, as is the decay due to chemical reactions of both species during the day.

The isoprene mixing ratio follows a similar trend and values to those measured during TROFEE by Karl et al. (2007) and GABRIEL by Eerdekens et al. (2008), with an increase in the early morning hours and almost constant values between 11:00 to 16:00 LT. Similarly, $\mathrm{OH}$ and $\mathrm{HO}_{2}$ have values similar to the ones observed during the GABRIEL campaign Eerdekens et al. (2008).

It is also important to analyze the ability of the MXL model in reproducing the vertical profile of the mixing ratio and the flux. The ISO mixing ratio is derived from the mixed-layer value $<\mathrm{ISO}>$ and the value in the free troposphere $\mathrm{ISO}_{F T}$ (in our numerical experiments equal to zero), while to construct the ISO-flux profile, we use the discontinuity value at the inversion $\triangle \mathrm{ISO}$ and the entrainment velocity calculated from the MXL model. These profiles are compared to the profiles calculated using the Large-Eddy Simulation technique (code Dutch Atmospheric Large-Eddy Simulation version 3, DALES), coupled to a chemistry module (Vilà-Guerau de Arellano et al., 2005). At DALES, we set the same chemical mechanism and chemical solver as well as the same initial and boundary condition summarized in Tables 1, 2 and 3. The horizontal and vertical grid lengths are $66 \mathrm{~m}$ and $20 \mathrm{~m}$, respectively.

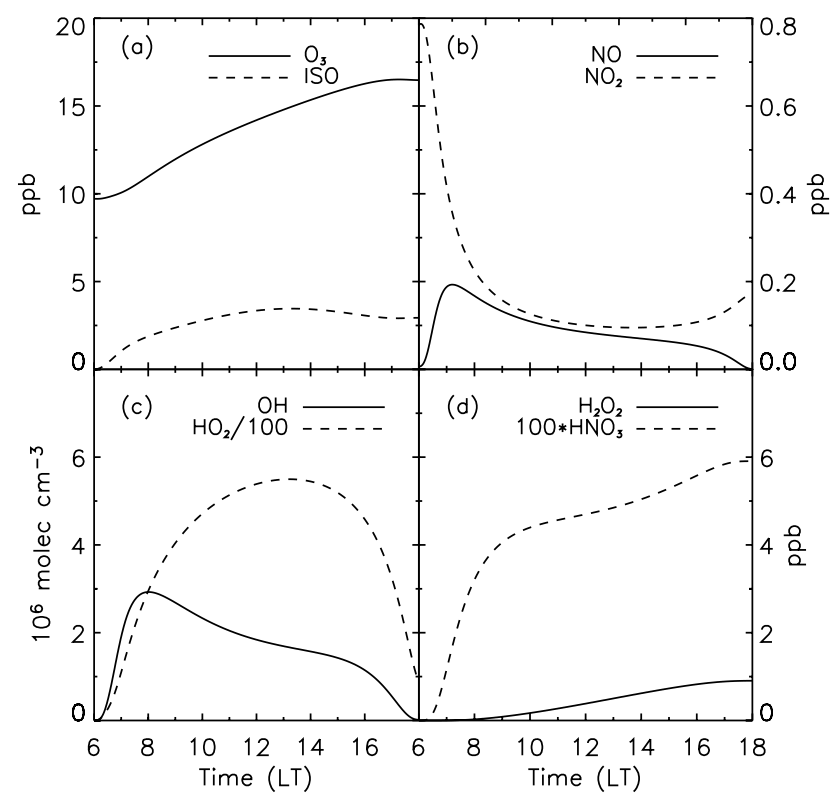

Fig. 2. Calculated diurnal evolution of (a) ozone $\left(\mathrm{O}_{3}\right)$ and isoprene (ISO), (b) nitric oxide (NO) and nitrogen dioxide $\left(\mathrm{NO}_{2}\right)$, (c) hydroxyl radical $(\mathrm{OH})$ and $\left(\mathrm{HO}_{2}\right)$ radical (in molec $\left.\mathrm{cm}^{-3}\right)$ and (d) hydrogen peroxide $\left(\mathrm{H}_{2} \mathrm{O}_{2}\right)$ and nitric acid $\left(\mathrm{HNO}_{3}\right)$. The initial mixing ratio in the $\mathrm{CBL}$ and the free troposphere and emission flux for the reference case are shown in Table 3.

Figure 3 presents the ISO-mixing ratio and ISO-flux profiles calculated by the MXL model and DALES at 12:00 LT (at this time the sensible, latent and ISO fluxes have reached their maximum values). We find that the ISO-mixing ratio profile calculated by DALES (one-hour averaged around 12:00 LT) is well mixed from $100 \mathrm{~m}$ to $1100 \mathrm{~m}$, indicating the strong mixing capacity of the upward thermals. Moreover, the characteristic time scale of ISO defined as $\tau_{c}=\left(k_{5} \mathrm{OH}\right)^{-1}$ is approximately $2 \mathrm{~h}$ at $12: 00 \mathrm{LT}$. This time scale indicates that this chemical reaction is relativately larger than the time scale of the CBL $(\approx 15-20 \mathrm{~min}$ ) allowing the compounds to mix faster than the chemical transformation. Above $1100 \mathrm{~m}$, there is a ISO-mixing ratio gradient characteristic of the stable stratification in the entrainment zone. Notice the large value of the entrainment zone depth $(\approx 400 \mathrm{~m})$ due to the 


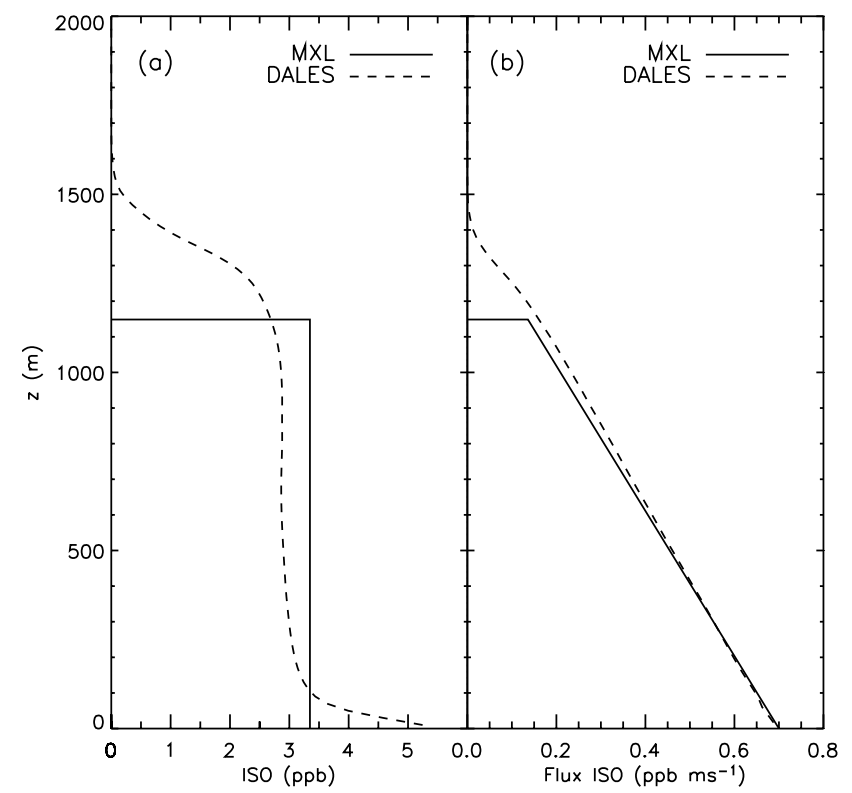

Fig. 3. Vertical profiles at 12:00 LT of the (a) ISO-mixing ratio and (b) ISO flux calculated using the MXL model (continuous line) and DALES (dashed line). The same initial and boundary conditions as described in Tables 2 and 3 are prescribed to obtain the DALES results. In DALES, the mixing ratio and flux were calculated by horizontally slab averaging the three-dimensional field of isoprene and the vertical velocity, and then averaging over one hour. Notice that at 12:00 LT, the fluxes of heat, moisture and isoprene have their maximum diurnal values.

low values of the initial morning potential temperature jump $(\Delta \theta=0.1 \mathrm{~K})$. In the bulk of the CBL, the difference from the MXL result is $0.3 \mathrm{ppb}$, showing the ability of the MXL model to reproduce the evolution of the main bulk vertical characteristics of isoprene during diurnal conditions. As assumed by mixed-layer theory, the sharp ISO mixing ratio gradients calculated by DALES at the surface $(z<100 \mathrm{~m})$ and in the entrainment zone $(1150 \mathrm{~m}>z>1550 \mathrm{~m})$ are not reproduced by the MXL model. However, the linear profile of the ISO flux (Fig. 3b) is in very good agreement with the profile calculated by DALES, indicating that the entrainment flux parameterized by Eq. (4) is able to satisfactorily capture, under convective conditions, the exchange flux of ISO between the growing convective boundary layer and the free troposphere.

\section{Estimating isoprene surface fluxes from mixing ratio boundary layer measurements}

\subsection{Methods}

As proposed by Guenther et al. (1996), Eq. (1) is rearranged to estimate the surface emission flux from atmospheric measurements of the reactant mixing ratios. The expression reads:

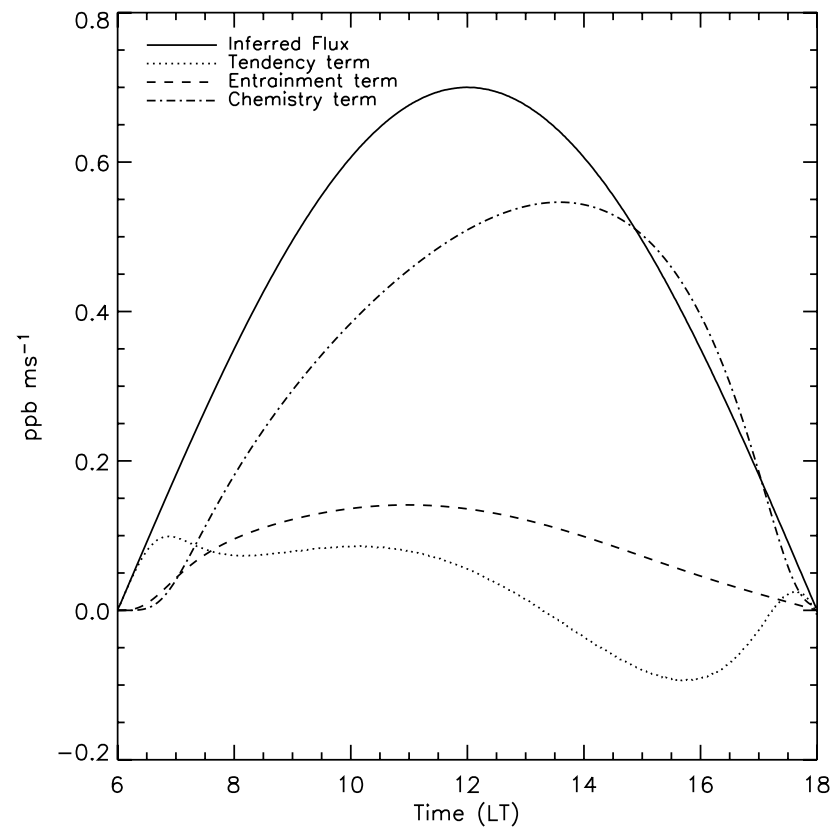

Fig. 4. Calculated diurnal evolution of the inferred ISO flux and the contributions of the tendency term, the entrainment term and the chemistry term. See Eq. (5) for the definition of each term. Notice that in that case, we obtain the prescribe value of the surface isoprene flux $0.7 \sin \left(\frac{\pi t}{t_{d}}\right) \mathrm{ppb} \mathrm{m} \mathrm{s}^{-1}$.

$$
(\overline{w s})_{s}=h\left[\frac{\partial<S>}{\partial t}+\left(U \frac{\partial<S>}{\partial x}+V \frac{\partial<S>}{\partial y}\right)-R\right]
$$

The right-hand term indicates that the inferred surface flux depends on the following four contributions: the tendency term $(\mathrm{T})$, the advection contribution (A), the chemical transformation (C) and the entrainment flux (E). Notice that all the four terms are modulated by the boundary layer evolution, in particular $h(t)$ (first three terms) and its corresponding derivative at time $w_{e}=\frac{\partial h}{\partial t}$. Here, it is important to mention that this retrieval expression is based on the linearity of the fluxes due to the quasi-steady state of the vertical gradient of the reactant mixing ratios. Species that react with a faster chemical reaction time scale than the turbulent time scale depart from this flux linearity. As shown by Vinuesa and VilàGuerau de Arellano (2003), their fluxes are strongly dependent on the chemical reaction term included in the flux budget equation. Our numerical experiments based on DALES (see Fig. 3) show that the isoprene gradient is in the quasisteady state and therefore the isoprene flux is linear (Fig. 3b).

In order to quantify the contribution of each term to estimating the diurnal variability of the isoprene surface flux, 
we apply Eq. (5), using the boundary-layer height obtained in the reference case (see Fig. 1) and mixing ratio evolution of the reactants shown in Fig. 2. Notice that this numerical experiment omits the influence of advection A on the thermodynamic and reactant variables. Therefore, we are able to retrieve the exact evolution of the prescribed flux $0.7 \sin \left(\frac{\pi t}{t_{d}}\right)$ (see Table 3) in order to be able to determine the importance of each term as a function of time.

Figure 4 shows the inferred flux and the contribution of the terms $\mathrm{T}, \mathrm{E}$ and $\mathrm{C}$. The chemical term modulated by the boundary layer height is the most important, contributing up to 70\% during the growth of the boundary layer (from 08:00 to 12:00 LT). In our study, the chemical term only contains the term of the reaction R5. However, the C term can be completed if other biogenic species are measured or taken into account in the chemical module of the MXL model. It is also during the morning period that the entrainment flux makes the larger contribution, which coincides with the largest values of the entrainment velocity because of the rapid growth in the morning CBL. Here, it is important to stress the advantage of using a MXL model coupled to a chemistry module in order to be able to reproduce the diurnal variability in the ratio of the entrainment flux to the surface emission flux for isoprene $\left(\beta_{\mathrm{ISO}}=\overline{\left(w^{\prime} \mathrm{ISO}_{e}^{\prime}\right.}\right) /\left(\overline{w^{\prime} \mathrm{ISO}_{s}^{\prime}}\right)$. Contrary to previous studies which neglect $\beta_{\text {ISO }}$ or assume it constant on time (Guenther et al., 1996; Karl et al., 2007), we are able to calculate $\beta_{\text {ISO-changes in the course of time due to the different }}$ stages of growth of the CBL. In our numerical experiment, $\beta_{\text {ISO }}$ reaches a maximum value of 0.3 at 07:00 LT and then decreases almost linearly to a value of 0.12 at the end of the afternoon.

Finally, the tendency term is the main term in the initial hour (06:00-07:00 LT), due to the increase in the ISO mixing ratio caused by the surface emission and the slow CBL growth during this period because of the small values of the sensible heat flux in the early morning hours. For term T, after the ISO mixing ratio has reached an almost constant value (see Fig. 2a), its contribution becomes smaller relative to the other terms and even changes sign, with the decay in the ISO mixing ratio related to the lower afternoon emissions and the chemical transformation with reaction (R5), see Table 1.

As Eq. (5) and Fig. 4 indicate, the evolution of the CBL plays a key role in retrieving the value of the ISO surface flux. It is therefore important to assess the potential deviation of the inferred flux due to uncertainties associated with the determination of $h(t),<\theta(t)>$ and $\Delta \theta(t)$. The following sections are devoted to analyzing the sensitivity of this calculation to the surface, upper air thermodynamic conditions, and horizontal advection of warm or cold air and subsidence. Our method follows the data treatment employed in field campaigns (Guenther et al., 1996; Spirig et al., 2004; Karl et al., 2007), and consists of the following steps:

1. Several numerical experiments are performed, characterized by changing only one initial variable or an ex-

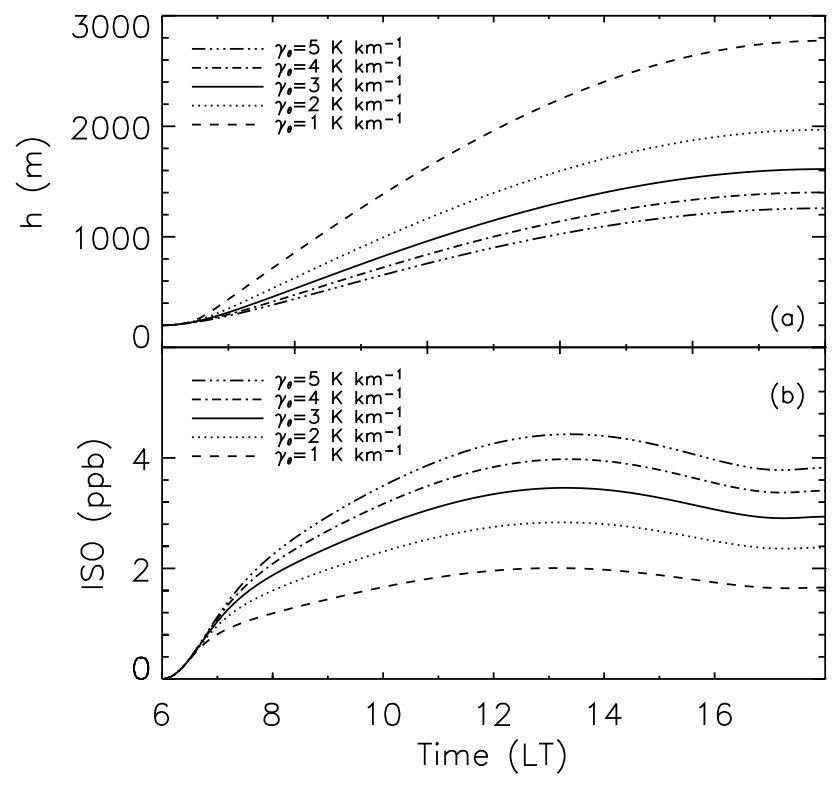

Fig. 5. Calculated diurnal evolution of (a) boundary layer height and (b) isoprene mixing ratio under different conditions of the potential temperature lapse rate $\left(\gamma_{\theta}\right)$. To produce these results, the same conditions as in Tables 2 and 3 are used, and the only variable changed is $\gamma_{\theta}$.

ternal boundary condition, more specifically, (a) the potential temperature lapse rate at the free troposphere, (b) the initial potential temperature jump, (c) the surface Bowen ratio (ratio of sensible heat flux to latent heat flux), (d) the horizontal advection of heat, and (e) vertical velocity subsidence. Figure 5 is an example of the sort of numerical experiment carried out in this case to study the influence of $\gamma_{\theta}$ on the mixing ratio of isoprene.

2. For each numerical experiment, a complete time series of the mixing ratio is obtained, similar to the one shown in Fig. 2. By so doing, we assume that these time series are those observed during the field campaign (synthetic observational data).

3. By using Eq. (5), we are able to retrieve the diurnal evolution of the ISO surface emission flux. Applying Eq. (5), we substitute the $h(t)$ and $w_{e}$ of each specific experiment with the one calculated in the reference case described by Table 2 and shown in Fig. 1c. Consequently, we assume that the time series of the reactants, the synthetic field observations, are free of errors. Therefore, we are able to quantify the degree of uncertainty related to inferring the surface emission flux due to inaccuracies in the determination of the dynamic evolution of the CBL. 


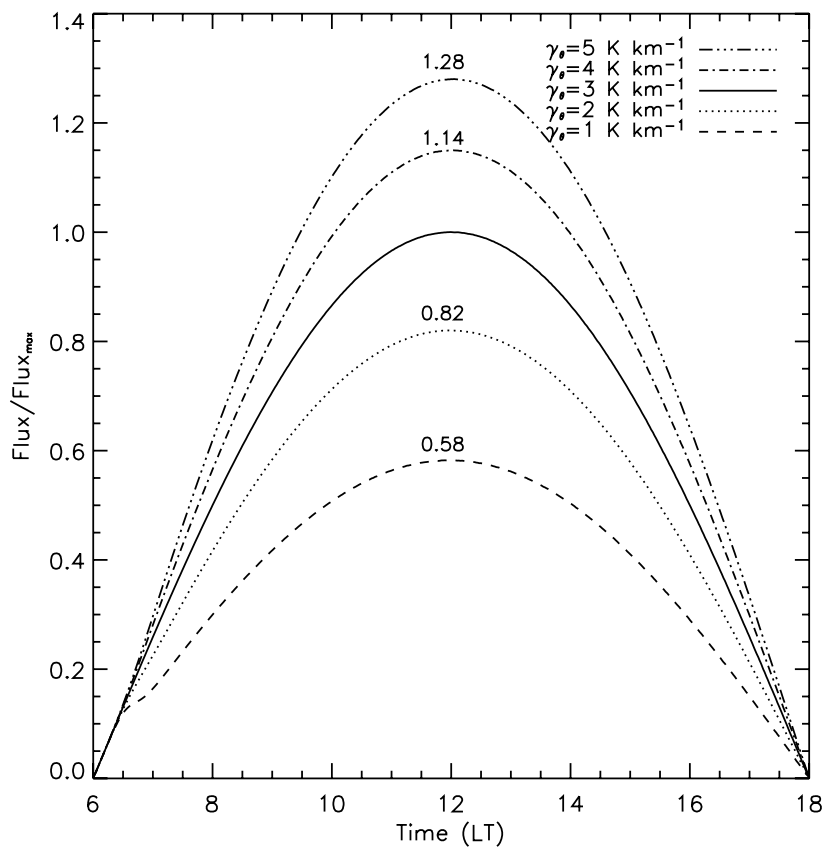

Fig. 6. Diurnal evolution of the inferred ISO flux. This flux is estimated using the mixing ratio of the reactants in each specific case (synthetic measurements), but using the boundary layer height of the reference case. In order to visualize the differences better, the ISO flux is normalized by the maximum value of the ISO flux (see Table 3). The case of $\gamma_{\theta}=3 \mathrm{~K} \mathrm{~km}^{-1}$ is the control experiment and the Flux/Flux $\max _{\max }$ is therefore equal to 1 at 12:00 LT. At each case, the ratio of Flux/Flux $\max$ at 12:00 LT is indicated in the figure.

\subsection{Sensitivity to the free troposphere and entrainment zone conditions}

By starting our analysis with the upper air conditions, our purpose was to stress the importance of these conditions for the development of the CBL. The conditions in the entrainment zone and above it are normally overlooked in the analysis of the field observations, and as we will show, they play a determinant role in the evolution of the characteristics of the CBL. In order to illustrate this, Fig. 5 shows a sensitivity analysis of the influence of the potential temperature lapse rate on the boundary layer height and the isoprene mixing ratio. We performed four extra numerical experiments with the same conditions as in Table 2, but now modifying the value of $\gamma_{\theta}$. The following values were prescribed: $5,4,2,1$ $\left(\mathrm{K} \mathrm{km}^{-1}\right)$. Notice in Fig. 5 that the larger $\gamma_{\theta}$-values prevent growth of the boundary layer by enhancing atmospheric stability above the CBL. In consequence, the dilution capacity of the CBL diminishes, yielding to a higher isoprene mixing ratio.

Figure 6 shows the diurnal variation in the inferred ISO surface flux for the five cases under study. These were calculated using the method described in Sect. 3.1. The re-

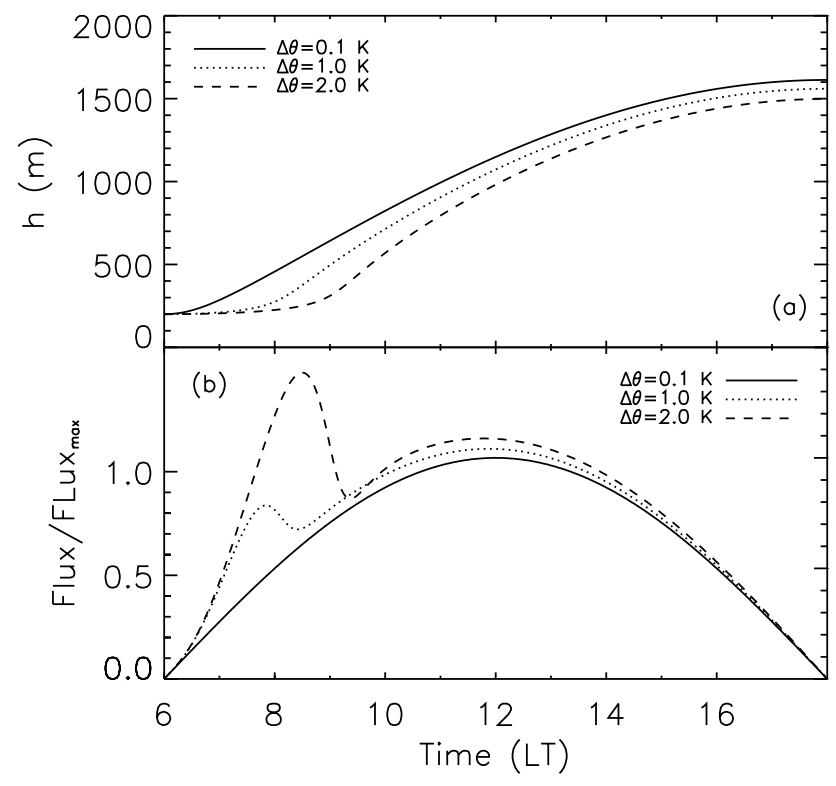

Fig. 7. Diurnal evolution of the (a) boundary layer height and (b) inferred ISO flux (made non-dimensional by the maximum value of the reference case at 12:00 LT). The inferred flux is estimated using the procedure described in Sect. 3.1. The sensitivity analysis performed is on the initial value of the potential temperature jump discontinuity prescribed at 05:00 LT. The other dynamic and chemistry conditions are equal to those presented in Tables 2 and 3.

sults were normalized by the maximum value of the reference case (Flux $\max$ ISO $=0.7 \mathrm{ppb} \mathrm{ms}^{-1}$ or $8 \mathrm{mgm}^{-2} \mathrm{~h}^{-1}$ at 12:00 LT) to show more clearly the differences. In the figure, we write down the ratio (Flux/Flux $\max _{\max }$ ) at 12:00 LT and in consequence for the reference case $\gamma_{\theta}=3 \mathrm{~K} \mathrm{~km}^{-1}$, the value of Flux/Flux $x_{\max }$ is equal to 1.

Notice first that in all cases the error introduced by not prescribing the correct $\gamma_{\theta}$ in the boundary layer height calculation always leads to large changes in the inferred ISO flux. A second interesting result is that these deviations are not linear. For instance, in the case of $\gamma_{\theta}=5 \mathrm{~K} \mathrm{~km}^{-1}$, we obtain a maximum deviation of 1.28 , whereas for the case $\gamma_{\theta}=1 \mathrm{~K} \mathrm{~km}^{-1}$, the Flux/Flux $\max$ at 12:00 LT is 0.58 . As Fig. 5a shows, a large value of $\gamma_{\theta}$ acts as a stronger capping inversion, leading to slower rate of growth of the CBL. This effect is taken into account in the MXL model by Eq. (2) (first right-hand term) since a larger $\gamma_{\theta}$ leads to a larger positive trend in the $\Delta \theta$ reinforcing the capping inversion. In turn, in the cases with small values of $\gamma_{\theta}$, entrainment is enhanced (represented by the second right-hand term) leading to a decrease on $\Delta \theta$.

The influence of the initial morning jump $\Delta \theta$ is studied at Fig. 7. This discontinuity is normally observed in the transition period from stable to unstable conditions and marks the difference in the chemistry composition between the residual layer and the CBL under development. In addition to the 
reference experiment, we studied two other cases, increasing the initial $\Delta \theta$ to 1 and $2 \mathrm{~K}$, respectively. Figure 7 a shows the evolution of the boundary layer for each numerical experiment. The initial rate of growth is significantly slowed by the initial capping inversion, around $3 \mathrm{~h}$, for the case $\Delta \theta=2 \mathrm{~K}$. As a result, the ISO-mixing ratio accumulates in the shallow morning boundary layer, which is prevented from growing by the stronger inversion. For instance, at 09:00 LT the ISO mixing ratio has the following maximum peak values: $2.4 \mathrm{ppb}$ (for $\Delta \theta=0.1 \mathrm{~K}$ ), $3.1 \mathrm{ppb}$ (for $\Delta \theta=1.0 \mathrm{~K}$ ) and $5.1 \mathrm{ppb}$ (for $\Delta \theta=2.0 \mathrm{~K}$ ). As Fig. $7 \mathrm{~b}$ shows the effect of the accumulation of ISO also influences the retrieval of the surface flux. If the initial $\Delta \theta$ was not adequately taken into account in the $h(t)$ calculation, we found large deviations in the inferred flux, which could last up to three hours after the start of the numerical experiment. This non-linear behavior of the retrieved ISO surface flux is therefore dependent on the initial potential temperature jump and the heat introduced by the sensible heat flux at the surface needed to erode the early morning inversion.

\subsection{Sensitivity to the Bowen ratio at the surface}

The partition of the net radiation into the sensible heat flux and the latent heat flux at the surface plays a crucial role in CBL development. As mentioned in Sect. 2.1, these turbulent fluxes need to be measured by the eddy covariance method or calculated from a land surface model coupled to the MXL model. In order to perform the numerical experiments, we need to assume that the net radiation $R_{n}$ is constant for all the experiments and equal to $600 \mathrm{~W} \mathrm{~m}^{-2}$ at 12:00 LT. In the reference experiment (Table 2), the maximum Bowen ratio $(B)$, defined as the ratio of the sensible heat flux to the latent heat flux at the surface, is 0.25 at 12:00 LT. Two additional cases were examined, one of which slightly increases the Bowen ratio $\left(B_{\max }=0.31\right.$ at $\left.12: 00 \mathrm{LT}\right)$, while the other decreases it $\left(B_{\max }=0.19\right)$.

Figure 8 shows the impact of the Bowen ratio on boundary layer growth. As expected, larger (smaller) values of $B$ leads to a more rapid (slower) CBL growth. At 18:00 LT, for $B_{\max }=0.31, h$ reaches a value of $1764 \mathrm{~m}$ and, for $B_{\max }=0.19$, $h$ is $1445 \mathrm{~m}$. Although these are relatively small variations in the Bowen ratio, the modified values of $h(t)$ have a relatively large impact on our inferences of the ISO surface flux (see Fig. 8b). Therefore, an uncertainty associated with the estimation of the partition of the net radiation into sensible heat flux and latent heat flux leads to deviations in the ISO flux throughout the diurnal period of the ISO emission flux. These deviations are larger around the maximum values of the surface turbulent fluxes. Similar to the sensitivity analysis for $\gamma_{\theta}$, the maximum deviations, $0.91\left(B_{\max }=0.19\right)$ and $1.12\left(B_{\max }=0.31\right)$ respectively, are non-linear.

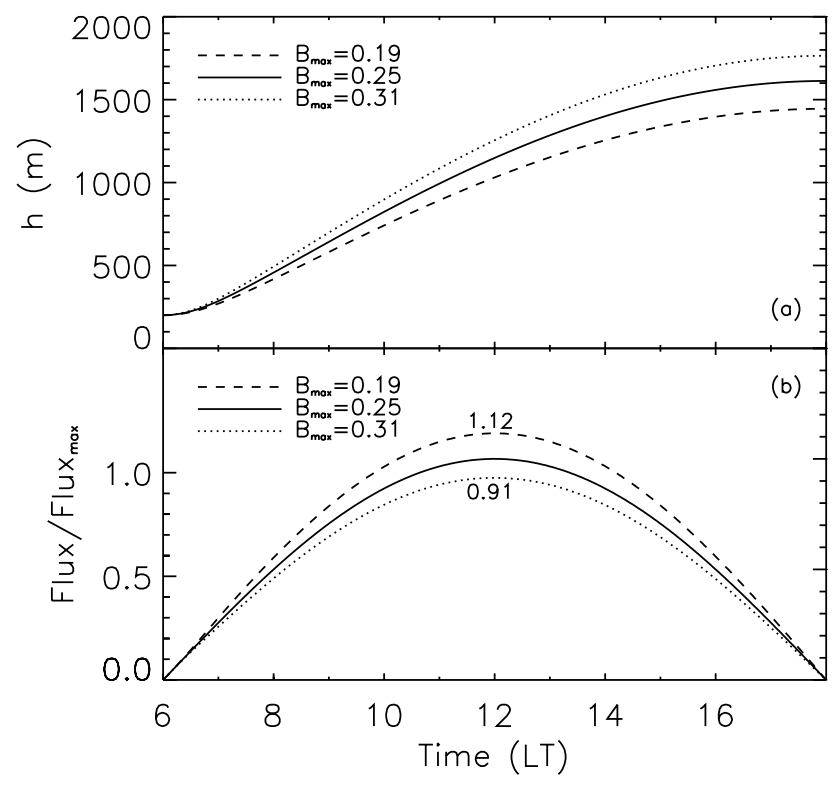

Fig. 8. Diurnal evolution of the (a) boundary layer height and (b) inferred ISO flux (made non-dimensional by the maximum value of the reference case at 12:00 LT). The inferred flux was estimated using the procedure described in Sect. 3.1. The sensitivity analysis was performed on the partition of the sensible and latent heat fluxes, expressed as the Bowen ratio. We have assumed the same net radiation $\left(600 \mathrm{~W} \mathrm{~m}^{-2}\right)$ for the three cases. The other dynamic and chemistry conditions are equal to those presented on Tables 2 and 3. At each case, the ratio of Flux/Flux $\max$ at 12:00 LT is indicated in the figure.

\subsection{Sensitivity to the horizontal advection of heat and to subsidence vertical velocity}

The other relevant process that contributes to the evolution of the value of the mixed layer is the horizontal and vertical advection of thermodynamic properties or reactants. The importance of each term in Eq. (5), whether entrainment or advection, strongly depends on the synoptic or mesoscale conditions, but both terms are always important contributors to the diurnal variability of the atmospheric compounds (CassoTorralba et al., 2008).

Since the main aim of the study was to determine the role of potential changes on $h(t)$, we focus here solely on the large horizontal advection of heat, 1.e., $U \frac{\partial<\theta>}{\partial x}+V \frac{\partial<\theta>}{\partial y}$. In doing so, we assume that our synthetic measurements of the reactant mixing ratio (in our case provided by the MXL model) account for all the variations due to emissions, entrainment and advection, and all uncertainties are related to our inability to calculate the diurnal variability in the CBL.

To this end, we designed two further numerical experiments that would take into account the advection of heat on the development of the boundary layer: warm air advected $\left(0.2 \mathrm{~K} \mathrm{~h}^{-1}\right)$ and cold air advected $\left(-0.2 \mathrm{~K} \mathrm{~h}^{-1}\right)$. Both large-scale advective tendencies are constant in time during 


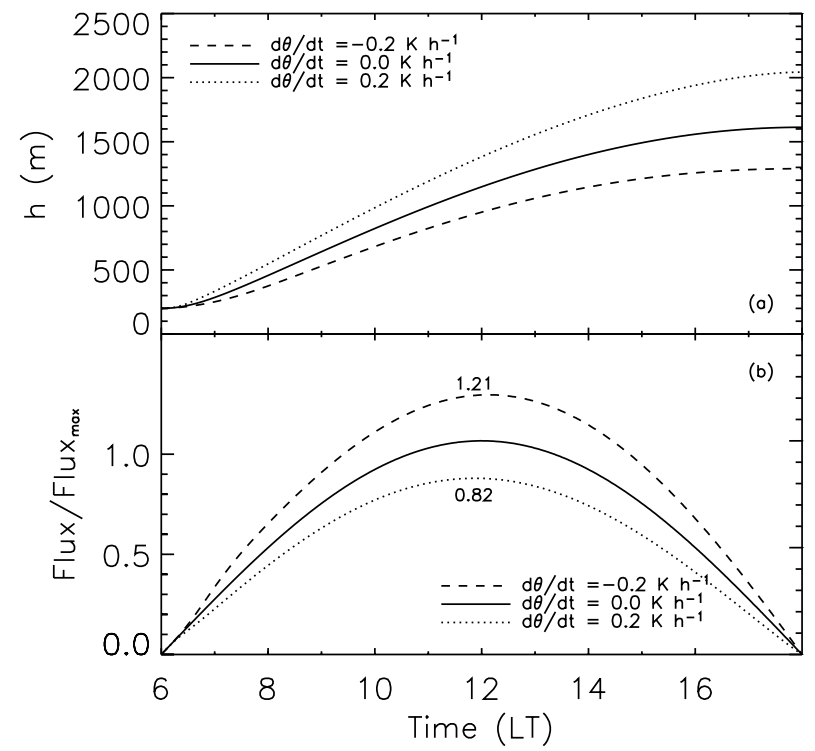

Fig. 9. Diurnal evolution of the (a) boundary layer height and (b) inferred ISO flux (made non-dimensional by the maximum value of the reference case at 12:00 LT). The inferred flux was estimated using the procedure described in Sect. 3.1. The sensitivity analysis was performed on the large-scale horizontal advection of potential temperature within the convective boundary layer. We assume that this large-scale forcing is constant on time from 06:00 LT to 12:00 LT. The other dynamic and chemistry conditions are equal to those presented on Tables 2 and 3. At each case, the ratio of Flux/Flux $\max$ at 12:00 LT is indicated in the figure.

the 12-h diurnal variation. Figure $9 \mathrm{a}$ shows the altitude of the boundary layer for these two cases and the reference case (see Table 2). In the experiment characterized by $U \frac{\partial<\theta>}{\partial x}=0.2 \mathrm{~K} \mathrm{~h}^{-1}$, the growth of the boundary layer was enhanced, since warm air transported into the CBL tends to reduce the $\Delta \theta$ value at the inversion. In both cases, the difference in the evolution of the boundary layer was significant. For instance, at 18:00 LT, the variations of the CBL height in the warm and cold advection cases with respect to the reference case were $431 \mathrm{~m}$ and $323 \mathrm{~m}$, respectively. As shown in Fig. 9b, the advection of heat in our estimation of $h(t)$ is omitted, the inferred ISO flux is either overestimated or underestimated. As in the sensitivity analysis discussed above, a rise in the height of the boundary layer driven by warm advection dilutes the reactants and the use of an inaccurate value of $h(t)$ consequently tends to underestimate the inferred ISO surface flux. The opposite effect occurs in the cases characterized by more shallow convective boundary layers.

Vertical subsidence plays a major role during the dry season in the Amazonian region, and therefore is interesting to study its impact on the boundary layer height evolution and subsequently in inferring the surface fluxes. As mentioned in Sect. 3.1, an estimation of $w_{s}$ must be ob- tained from mesoscale or global synoptic models. In the MXL model, it can be introduced using the following expression: $w_{s}=-z \operatorname{Div}\left(U_{\text {hor }}\right)$ (Lilly, 1968), where $\operatorname{Div}\left(U_{\text {hor }}\right)$ is the divergence of the mean wind horizontal components and $z$ is the height above ground level. In order to determine the sensitivity of the inferred isoprene fluxes to subsidence, we performed a couple of numerical simulations using the following values for $\operatorname{Div}\left(U_{\mathrm{hor}}\right)=5.10^{-6} \mathrm{~s}^{-1}$ and $\operatorname{Div}\left(U_{\text {hor }}\right)=1.10^{-5} \mathrm{~s}^{-1}$ (not shown in the figure). In both cases, the dilution capacity of the CBL decreases influenced by the subsidence of warm air and as a result we obtained inferred fluxes that are large by $5 \%$ and $21 \%$ compared to the maximum value of the reference case. In that respect, vertical subsidence motions act in a similar way to the cases in which $\gamma_{\theta}$ equal to 4 or $5 \mathrm{~K} \mathrm{~km}^{-1}$ at Fig. 6 .

In closing this analysis on the influence of boundary layer characteristics in the retrieval of surface fluxes using boundary layer techniques, it is important to mention that other widely used methods like the mixed-layer gradient or variance method (Davis et al., 1994; Helmig et al., 1998; Karl et al., 2007) are also influenced by the evolution of the boundary layer height and the dynamic conditions in the upper part of the CBL. For instance, the mixed-layer gradient technique infers the emission surface flux from the mean mixing ratio gradient, the convective velocity scaling $\left(w_{*}\right)$, the entrainment flux and two dimensionless bottom up and top down gradients ( $g_{b}$ and $g_{t}$, Patton et al., 2003). Using a similar notation as in Eq. (5), the inferred surface flux reads:

$$
(\overline{w s})_{s}=-\frac{h w_{*}}{g_{b}}\left(\frac{\partial S}{\partial z}\right)-\left(\frac{g_{t}}{g_{b}}\right)\left(w_{e} \Delta S\right) .
$$

As shown by Eq. (6), and similar to the mixed-layer retrieval technique defined by Eq. (5), the first right hand side term shows the modulation of the gradient term by the boundary layer height. The second term is also dependent on the boundary layer dynamics through out the entrainment velocity and the dependence of the functions $g_{b}$ and $g_{t}$ on the boundary layer height. Similar arguments hold for the variance method.

\section{Conclusions and suggestions for future field campaigns}

We have reviewed the assumptions and uncertainties associated with the use of the mixed-layer technique to infer surface emission fluxes from atmospheric concentration observations. We discussed how the inferred surface fluxes are modulated by the temporal variation in the height of the boundary layer and the exchange flux between the free troposphere and the CBL. We particularly emphasize studying the sensitivity of the technique to variables, initial and external conditions that determine the diurnal variability of the evolution of the CBL. We first showed, by comparing the 
mixed-layer model with large-eddy simulation results, that the mixed-layer model is capable of capturing the essential processes that control the evolution of the reactants. As has been demonstrated in previous studies, this technique is very useful as a way of retrieving fluxes from upper atmospheric concentration measurements. However, the retrieved fluxes largely depend on the accurate calculation or measurement of the boundary layer height and the concentration of the reactants in and above the CBL.

In order to determine these dependences, we began our study by analyzing the uncertainties associated with the conditions in the upper region of the convective boundary layer, namely the entrainment (inversion) zone. We find large deviations in the retrieval of the surface fluxes throughout the diurnal period, which are highly dependent on the temperature lapse rate and the potential temperature jump in the transition period between the stable and convective diurnal conditions. An uncertainty of $\pm 1 \mathrm{~K} \mathrm{~km}^{-1}$ in the value of the lapse rate leads to underestimation/overestimation of the isoprene flux emission of between 15-20\%. The retrieval of fluxes in the early morning hours is largely dependent on the initial thermodynamic conditions represented by the potential temperature discontinuity between the CBL value and the residual value. As we have shown, a larger potential temperature jump value enhances the accumulation of emitted atmospheric compounds, which results in overestimation of the retrieved surface fluxes.

The correct determination of the partition of the net radiation into sensible and latent heat flux also has a large influence on the inferred fluxes. Similar results were found when we analyzed the roles of vertical subsidence and the advection of cold/warm air masses in determining the isoprene flux. The numerical simulations presented here found that neglecting advection produces overestimation/underestimation of up to $20 \%$ of the inferred surface isoprene flux. It must be stressed that all the deviations are nonlinear, due to the close coupling between surface and entrainment processes in the development of the CBL. Therefore, in applying the MXL technique, we need to solve simultaneously the dynamics and chemistry of the processes involved. The sensitivity analysis is also valid for other boundary-layer techniques employed to retrieve the surface fluxes (e.g. the gradient or variance method), since their expressions depend explicitly on the boundary layer height and entrainment flux determination procedure.

In view of the results presented above, our recommendation for minimizing the uncertainties related to the development of the CBL in estimating the surface emission fluxes for the reactants is to measure continuously the boundary layer height using wind profiler or lidar instruments. In the absence of such measurement, and as shown in this study, a coupled model of the dynamics and chemistry of the CBL is a very satisfactory alternative. In order to obtain reliable model results, the following initial and boundary conditions need to be measured:
1. Eddy covariance measurements of the sensible and latent heat flux in order to determine the extent of the surface forcing of the CBL. In the absence of these data, the MXL model can be coupled to a land-surface scheme providing that we have the initial and boundary conditions to run this model.

2. Early morning profile (using for instance a tethered balloon or an aircraft) of the thermodynamic variables to take the potential temperature and specific moisture jump into account. The profiles will also provide the necessary information about the lapse rate of temperature and moisture in the residual layer or free troposphere.

3. Measurements or calculations from a large-scale atmospheric chemistry model of the concentration of the reactants in and above the ABL in the transition period from stable to unstable diurnal conditions.

4. Estimation of the horizontal advective and vertical subsidence terms using either calculations performed by mesoscale models or a global model, i.e. ECMWF, or by an horizontal array of measurement stations (for the horizontal advective terms).

These surface and upper air conditions observations are essential to ensure accurate estimates of the inferred emission fluxes of reactants from atmospheric concentration observations using boundary-layer techniques. Finally, the MXL model with the chemistry module is available upon request to the authors.

Our research attempts to provide a guidance to obtain a more balance approach between meteorological and atmospheric chemistry studies within the boundary layer. We have focused on the uncertainty effects of boundary layer dynamics in inferring surface emission fluxes. However, as the observational analysis recently presented by Karl et al. (2007); Eerdekens et al. (2008), there are still large uncertainties associated to the measurements of isoprenes and even more of the hydroxyl radical. Therefore, point 3 in the conclusions represents a challenge in the retrieval of surface fluxes of atmospheric reactive compounds.

Acknowledgements. The large-eddy simulations were performed at SARA under the National Computer Faculty contract (NCF SG060-08).

Edited by: J. Rinne

\section{References}

Andreae, M., Artaxo, P., Brandao, C., Carswell, F., Ciccioli, P., Costa, A. L., Culf, A. D., Esteves, J. L., Gash, J., Grace, J., Kabat, P., Lelieveld, J., Malhi, Y., Manzi, A. O., Meixner, F. X., Nobre, A. D., Nobre, C., Ruivo, M. D. L. P., Silva-Dias, M. A., 
Stefani, P., Valentini, R., von Jouanne, J., and Waterloo, M.: Biogeochemical cycling of carbon, water, energy, trace gases, and aerosols in Amazonia: the LBA-EUSTACH experiment, J. Geophys. Res., 107, 8066, doi:10.1029/2001JD000524, 2002.

Angevine, W. M., Grimsdell, A. W., McKeen, A., and Warnock, J. M.: Entrainment results from the Flatland boundary layer experiments, J. Geophys. Res., 103, 13689-13702, 1998.

Betts, A. K.: Non-precipitating cumulus convection and its parameterization, Q. J. Roy. Meteorol. Soc., 99, 178-196, 1973.

Betts, A. K.: FIFE atmospheric boundary layer methods, J. Geophys. Res., 97, 18523-18531, 1992.

Betts, A. K. and Jacob, C.: Evaluation of the diurnal cycle of precipitation, surface thermodynamics, and surface fluxes in the ECMWF model using LBA data, J. Geophys. Res., 107, 8045, doi:10.1029/2001JD000427, 2002.

Carson, D. J.: The development of a dry inversion-capped convectively unstable boundary layer, Q. J. Roy. Meteorol. Soc., 99, 450-467, 1973.

Casso-Torralba, P., Vilà-Guerau de Arellano, J., Bosveld, F., Soler, M., Vermeulen, A., Werner, C., and Moors, E.: Diurnal and vertical variability of the sensible heat and carbon dioxide budgets in the atmospheric surface layer, J. Geophys. Res., 113, D12119, doi:10.1029/2007JD009583, 2008.

Conzemius, R. and Fedorovich, E.: Dynamics of sheared convective boundary layer entrainment. Part II: Evaluation of bulk model predictions of entrainment flux, J. Atmos. Sci., 63, 1179-1199, 2006.

Davis, K. J., Lenschow, D. H., and Zimmerman, P.: Biogenic nonmethane hydrocarbon emissions estimated from tethered ballon observations, J. Geophys. Res., 99, 25587-25598, 1994.

Dickerson, R. R., Stedman, D. H., and Delany, A. C.: Direct measurement of ozone and nitrogen dioxide photolysis rate in the troposphere, J. Geophys. Res., 87, 4933-4946, 1982.

Eerdekens, G., Ganzeveld, L., Vilà-Guerau de Arellano, J., Klüpfel, T., Sinha, V., Yassaa, N., Williams, J., Harder, H., Kubistin, D., Martinez, M., and Lelieveld, J.: Flux estimates of isoprene, methanol and acetone from airborne PTR-MS measurements over the tropical rainforest during the GABRIEL 2005 campaign, Atmos. Chem. Phys. Discuss., 8, 12903-12969, 2008, http://www.atmos-chem-phys-discuss.net/8/12903/2008/.

Fedorovich, E.: Modeling the atmospheric convective boundary layer within a zero-order jump approach: An Extended theoretical framework, J. Appl. Meteorol., 34, 1916-1928, 1995.

Fuentes, J. D., Lerdau, M., Atkinson, R., Baldocchi, D., Bottenhiem, J. W., Ciccioli, P., Lamb, B., Geron, C., Gu, L., Guenther, A., Sharkey, T. D., and Stockwell, W.: Biogenic hydrocarbons in the atmospheric boundary layer: A review, B. Am. Meteorol. Soc., 81, 1537-1575, 2000.

Guenther, A., Zimmerman, P., Klinger, L., Greenberg, J., Ennis, C., Westberg, H., Allwine, G., and Geron, C.: Estimates of regional natural volatile organic compound fluxes from enclosure and ambient measurements, J. Geophys. Res., 101, 1345-1359, 1996.

Helmig, D., Balsley, B., Davis, K., Kuck, L. R., Jensen, M. L., Bognar, J., Smith, T., Vasquez-Arrieta, R., Rodriguez, R., and Birks, J.: Vertical profiling and determination of landscape fluxes of biogenic nonmethane hydrocarbons within the planetary boundary layer in the Peruvian Amazon, J. Geophys. Res., 103, 2551925532, 1998.

Karl, T., Guenther, A., Yokelson, R. J., Greenberg, J., Poto- snak, M., Blake, D. R., and Artaxo, P.: The tropical forest and fire emissions experiment: Emission, chemistry, and transport of biogenic volatile organic compounds in the lower atmosphere over Amazonia, J. Geophys. Res., 112, D18302, doi:10.1029/2007JD008539, 2007.

Kim, S. W., Pang, S. U., Pino, D., and Vilà-Guerau de Arellano, J.: Parameterization of entrainment in a sheared convective boundary layer using a first-order jump model, Bound.-Layer Meteorol., 120, 455-475, 2006.

Krol, M. C., Molemaker, M. J., and Vilà-Guerau de Arellano, J.: Effects of turbulence and heterogeneous emissions on photochemically active species in the convective boundary layer, J. Geophys. Res., 105, 6871-6884, 2000.

Lauback, J. and Fritsch, H.: Convective boundary layer budgets derived from aircraft data, Agric. For. Meteor., 111, 237-263, 2002.

Lilly, D.: Models of cloud-topped mixed layers under s strong inversion, Q. J. Roy. Meteor. Soc., 94, 292-309, 1968.

Patton, E. G., Sullivan, P. P., and Davis, K. J.: The influence of a forest canopy on top-down and bottom-up diffusion in the planetray boundary layer, Q. J. Roy. Meteor. Soc., 129, 1415-1434, 2003.

Pino, D., Vilà-Guerau de Arellano, J., and Duynkerke, P. G.: The contribution of shear to the evolution of a convective boundary layer, J. Atmos. Sci., 60, 1913-1926, 2003.

Spirig, C., Guenther, A., Greenberg, J. P., Calanca, P., and Tarvainen, $\mathrm{V}$.: Tethered balloon measurements of biogenic volatile organic compounds at a Boreal forest site, Atmos. Chem. Phys., 4, 215-229, 2004, http://www.atmos-chem-phys.net/4/215/2004/.

Stockwell, W. R., Middleton, P., Chang, J. S., and Tang, X.: The second generation regional acid deposition model chemical mechanism for regional air quality modeling, J. Geophys. Res., 95, 16343-16367, 1990.

Tennekes, H.: A model for the dynamics of the inversion above a convective boundary layer, J. Atmos. Sci., 30, 558-567, 1973.

van Dijk, S. M., Gut, A., Kirkman, G. A., Meixner, F. X., Andreae, M. O., and Gomes, B. M.: Biogenic NO emissions from forest and pasture soils: Relating laboratory studies to field measurements, J. Geophys. Res., 107, D208058, doi:10.1029/2001JD000521, 2002.

Vilà-Guerau de Arellano, J., Kim, S.-W., Barth, M. C., and Patton, E. G.: Transport and chemical transformations influenced by shallow cumulus over land, Atmos. Chem. Phys., 5, 3219-3231, 2005, http://www.atmos-chem-phys.net/5/3219/2005/.

Vinuesa, J. F. and Vilà-Guerau de Arellano, J.: Fluxes and covariances of reacting scalars in the convective boundary layer, Tellus, 55B, 935-949, 2003.

Westberg, H., Lamb, B., Hafer, R., Hills, A., Shepson, P., and Vogel, C.: Measurement of isoprene fluxes at the PROPHET site, J. Geophys. Res., 106, 24347-24358, 2001.

Yokelson, R. J., Karl, T., Artaxo, P., Blake, D. R., Christian, T. J., Griffith, D. W. T., Guenther, A., and Hao, W. M.: The Tropical Forest and Fire Emissions Experiment: overview and airborne fire emission factor measurements, Atmos. Chem. Phys., 7, 5175-5196, 2007, http://www.atmos-chem-phys.net/7/5175/2007/.

Zimmerman, P., Greenberg, J. P., and Westberg, C.: Measurement of atmospheric hydrocarbons and biogenic emission fluxes in the Amazon boundary layer, J. Geophys. Res., 93, 1407-1416, 1988. 